\title{
Analysis of the SARS-CoV-2 spike protein glycan shield: implications for immune recognition
}

Oliver C. Grant, David Montgomery, Keigo Ito, Robert J. Woods*

Complex Carbohydrate Research Center, University of Georgia, 315 Riverbend Rd, Athens, GA 30602

\section{Corresponding Author}

*Mailing address: 315 Riverbend Road, Athens, GA 30602.

Tel.: 706-542-4454. Fax: 706-542-4412. E-mail: rwoods@ccrc.uga.edu 


\begin{abstract}
Here we have generated 3D structures of glycoforms of the spike (S) glycoprotein from SARS-CoV-2, based on reported 3D structures and glycomics data for the protein produced in HEK293 cells. We also analyze structures for glycoforms representing those present in the nascent glycoproteins (prior to enzymatic modifications in the Golgi), as well as those that are commonly observed on antigens present in other viruses.

These models were subjected to molecular dynamics (MD) simulation to determine the extent to which glycan microheterogeneity impacts the antigenicity of the $\mathrm{S}$ glycoprotein. Lastly, we have identified peptides in the $S$ glycoprotein that are likely to be presented in human leukocyte antigen (HLA) complexes, and discuss the role of S protein glycosylation in potentially modulating the adaptive immune response to the SARS-CoV-2 virus or to a related vaccine.

The 3D structures show that the protein surface is extensively shielded from antibody recognition by glycans, with the exception of the ACE2 receptor binding domain, and also that the degree of shielding is largely insensitive to the specific glycoform. Despite the relatively modest contribution of the glycans to the total molecular weight (17\% for the HEK293 glycoform) the level of surface shielding is disproportionately high at $42 \%$.
\end{abstract}

\title{
Introduction
}

The present COVID-19 pandemic has led to over a million confirmed infections globally with a fatality rate of approximately 5 percent (1) since the first reports of a severe acute respiratory syndrome (SARS) infection by a novel coronavirus (SARS-CoV-2) at the end of 2019. As of April 2020, there is still no vaccine or approved therapeutic to treat this disease. Here we examine the structure of the SARS-CoV-2 envelope spike (S) protein that mediates host cell infection, with a specific focus on the extent to which glycosylation masks this virus antigen from the host immune response.

Viral envelope proteins are often modified by the attachment of complex glycans that can account for up to half of the molecular weight of these glycoproteins, as in HIV gp120 (2). The glycosylation of these surface antigens helps the pathogen evade recognition by the host immune system by cloaking the protein surface from detection by antibodies, and can influence the ability of the host to raise an effective adaptive immune response $(3,4)$ or even be exploited by the virus to enhance infectivity (5). Additionally, because the virus hijacks the host cellular machinery for replication and subsequent glycosylation, the viral glycan shield may be composed of familiar host glycans; thereby suppressing an anti-carbohydrate immune response (6).

Fortunately, the innate immune system has evolved a range of strategies for responding to glycosylated pathogens (7), but antigen glycosylation nevertheless complicates the development of vaccines (8). Over time, the protein sequences in viral antigens undergo mutations (antigenic drift), which can alter the species specificity of the virus (9), modulate its infectivity (10), and alter the antigenicity of the surface proteins (11). These mutations can also impact the degree to which the protein is glycosylated by creating new or removing existing locations of the glycans (glycosites) on the antigens $(12,13)$. Varying surface antigen glycosylation is thus a mechanism by which new virus strains can evade the host immune response (12), and attenuate the efficacy of existing vaccines (8). 
Very recently, a cryo-EM structure of the SARS-CoV-2 S glycoprotein has been reported (14), which led to conclusion that, like the related protein from the 2002 - 2003 SARS pandemic (SARS-CoV-1) (15), the CoV-2 S protein is also extensively glycosylated (14). Furthermore, an analysis of the glycan structures present at each glycosite in the $\mathrm{S}$ protein produced recombinantly in human embryonic kidney (HEK) 293 cells has also been recently reported (16).

Here we have generated 3D structures of several glycoforms of the SARS-CoV-2 S glycoprotein, in which the glycans represent those present in the $S$ protein produced in HEK293 cells (16), as well as those corresponding to the nascent glycoprotein (prior to enzymatic modifications in the Golgi apparatus), and those that are commonly observed on antigens present in other viruses (17-19). We have subjected these models to long molecular dynamics (MD) simulations and compared the extent to which glycan microheterogeneity impacts epitope exposure. Additionally, we have identified peptides in the S protein that are likely to be presented in human leukocyte antigen (HLA) complexes, and discuss the role of $\mathrm{S}$ protein glycosylation in modulating the adaptive immune response to the SARS-CoV-2 virus or to a related vaccine.

The impact of glycosylation on the ability of antibodies to bind to a pathogenic glycoprotein may be estimated by quantifying the fraction of the surface area of the protein antigen that is physically shielded by glycans from antibody recognition. However, glycans display large internal motions that prevents their accurate description by any single 3D shape, in contrast to proteins $(20,21)$. Fortunately, MD simulations can play a key role by accurately predicting the 3D shapes and motions of glycans, as confirmed by comparison to solution NMR data (22-24), and such simulations have been widely applied to glycoproteins (17, 25-28). Here we have performed MD simulations with the GLYCAM06/AMBER force field, which was developed for simulations of carbohydrates, carbohydrate-protein complexes and glycoproteins (29-31), and use the data to assess the impact of glycosylation on the immunogenic and antigenic properties of the $\mathrm{S}$ glycoprotein.

\section{Results}

Model glycoforms. It is well established that there is a strong dependence of both the composition and relative glycan abundance (glycan microheterogeneity) on the cell type used for glycoprotein production. And there is a large body of data relating to the influence of host cell line on viral envelop protein glycosylation. For example, a glycomics analysis of influenza A virus produced in five different cell lines, all of relevance to vaccine production, led to the observation of profound differences in the compositions of the glycans at a given site; with structures varying from paucimannose (Sf9 cells) to core-fucosylated hybrid with bisecting $\mathrm{N}$-acetylglucosamine (Egg) to sialylated biantennary glycans (HEK293) (19). For these reasons, we have modeled the $\mathrm{S}$ glycoprotein with reported site-specific glycosylation (16), as well as hypothetical homogeneously glycosylated glycoforms of the high mannose (M9), paucimannose (M3), biantennary complex (Complex) and core-fucosylated biantennary complex (Complex Core F) types. Comparisons among the glycoforms permits an assessment of the impact of cell-based differential glycan processing on $\mathrm{S}$ protein antigenicity.

Assessment of the impact of glycosylation on antigenicity. We subjected the five glycoforms of the CoV-2 S glycoprotein to MD simulation and interpreted the results in 
terms of the impact of glycan structure on the theoretical S glycoprotein antigenic surface area (Figure 1, Supplementary Figure S1, Table 1). A series of 3D structure snapshots of the simulation were taken at $1 \mathrm{~ns}$ intervals and analysed in terms of their ability to interact with a spherical probe based on the average size of hypervariable loops present in an antibody complementarity determining region (CDR) (Figure 3). The percentage of simulation time each residue was exposed to the antibody accessible surface area (AbASA) probe was calculated and plotted onto both the 3D structure (Figure 1) and sequence (Figure 2). The average AbASA over the course of the simulations was also calculated for each glycoform and compared to non-glycosylated protein (Table 1).
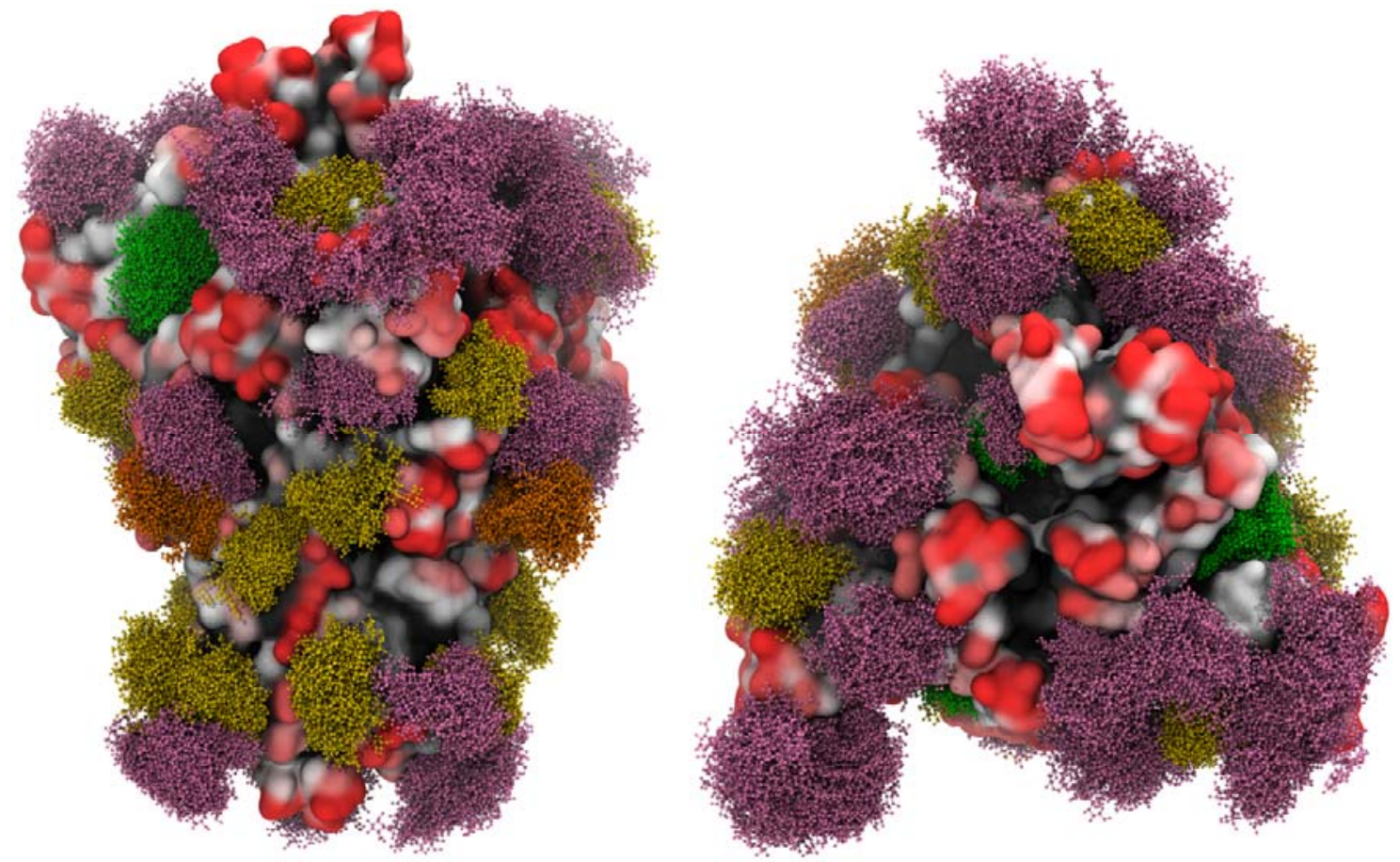

Figure 1. Overlay of snapshots from MD simulation of the S glycoprotein with sitespecific glycosylation. The glycans are shown in ball-and-stick representation: M9 (green), M5 (dark yellow), hybrid (orange), complex (pink) (See Supplementary Table S1 for details). The protein surface is colored according to antibody accessibility from black to red (least to most accessible). Images generated using Visual Molecular Dynamics (VMD) (32) version 1.9.3.

The data indicate that uniform glycosylation with the smallest of the glycans (paucimannose, M3), which is a sub-structure within all $\mathrm{N}$-linked glycans, provided the least shielding of the S protein (29\% coverage), leaving $71 \%$ of the surface exposed to an antibody probe relative to the same protein with no glycosylation. In contrast, the largest high mannose N-linked glycans (M9), which corresponds to the nascent glycoform that would exist prior to processing through the Golgi apparatus, led to the highest level of surface shielding (47\%). The level of cloaking offered by the two types of complex glycans are not significantly different from that of M9 at 45-47\% surface shielding. Glycosylation based on the S glycoprotein produced recombinantly in HEK293 resulted $42 \%$ of the surface being shielded from antibody recognition; a value that is comparable to that for the models based on uniform M9 or Complex glycans. There is a strong correlation $\left(\mathrm{R}^{2}=0.98\right)$ between the total molecular weight of the glycans and the net shielding of the protein surface, however it is 
notable that the glycans disproportionately block the accessibility of the surface to the antibody probe. This result is indicative of the high density of the glycans on the $\mathrm{S}$ glycoprotein surface.

The results from the CDR accessibility analysis are consistent with the conclusion that antigenicity of the $\mathrm{S}$ protein is largely insensitive to glycan microheterogeneity, with the exception of the glycoform composed solely of M3 glycans. Nevertheless, differences in glycosylation may impact other structural features, such as local interactions between the glycan and the protein surface, or local structural fluctuations in either the protein or glycan conformations that are only partially captured by the exposed surface area analysis.

Table 1. SARS-CoV-2 S glycoprotein antigenic surface areas $\left(\AA^{2}\right)$ as a function of glycoform.

\begin{tabular}{lccc}
\hline Glycoform & $\begin{array}{l}\text { Average antibody } \\
\text { accessible surface } \\
\text { area (AbASA) }\end{array}$ & $\begin{array}{l}\text { Percentage of AbASA } \\
\text { shielded by glycans }\end{array}$ & $\begin{array}{l}\text { Glycan percentage } \\
\text { of total molecular } \\
\text { weight }\end{array}$ \\
\hline M3 & & $29.4 \%$ & $11.7 \%$
\end{tabular}

M9: $44,184 \pm 1.1 \% \quad 46.8 \% \quad 21.6 \%$

\section{Complex}

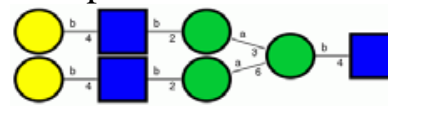

$45,571 \pm 1.6 \%$

$45.1 \%$

$19.4 \%$

Complex Core F

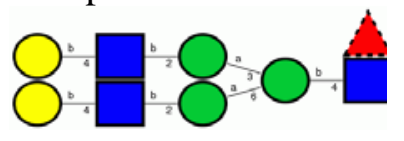

$43,943 \pm 2.0 \%$

$47.1 \%$

$20.7 \%$

HEK293 site-specific glycosylation

$48,322 \pm 0.7 \%$

$41.8 \%$

$17.0 \%$

Non-glycosylated

$83,041 \pm 2.8 \%$

$0 \%$

$0 \%$

${ }^{\mathrm{a}}$ Surface areas were computed with the Naccess software (33), version 2.1.1. ${ }^{\mathrm{b}}$ Percentage $=$ $(1-$ AbASA/83,041)*100\%.

A visual examination of the glycoform 3D structures (Figure 1 and Supplementary Figure S1) indicates that the most exposed epitopes comprise the ACE2 receptor site, specifically the apex region of the $\mathrm{S} 1$ domain when that domain is in the open conformation. The large extent of RBD exposure is quantified in Figure 2c. Moreover, the extensive motion displayed by each glycan illustrates that no single static model could fully capture the extent of glycan shielding. It can also be observed that a ring of antigenic sites appears to encircle the S1 domain, independent of glycoform. Unlike the extremely high level of glycan 
shielding in gp120 that challenges HIV vaccine development $(34,35)$, the level of shielding by glycans in the $\mathrm{S}$ protein is more moderate, with approximately $42 \%$ of the surface potentially inaccessible to antibodies.

Adaptive immune response to SARS-CoV-2. Beyond a role in shielding the underlying protein from recognition by antibodies, the glycans on pathogenic proteins may also attenuate the ability of the host immune system to raise antibodies against any epitopes that include the glycan. In a T-cell dependent adaptive immune response, peptides from the pathogen are presented on antigen presenting cells by major histocompatibility complex II molecules, known as human leukocyte antigen (HLA) complexes. HLA complexes have preferred peptide motifs, and based on a knowledge of these preferences it is possible to predict which peptides in a protein are likely to be HLA antigens $(36,37)$. However, when that peptide contains a glycosylation site, the ability of the peptide to be presented by an HLA may be compromised, if for example the peptide cannot bind to the HLA molecule due to the steric presence of the glycan. However, glycopeptides may be presented in HLA complexes if the glycan is small enough (38) or if it is found on the end of the peptide antigen where it doesn't interfere with HLA binding (39). The glycan-mediated shielding of predicted HLA antigens (Supplementary Table S2) derived from the S protein are shown in Figure 4 and Supplementary Figures S2 and S3 for all HLA peptide sequences that also contain a glycosite.

As expected, glycosylation consistently decreased the surface exposure of the residues proximal to the glycosites (Figure 2c), but also led to non-sequential changes in exposure, as a result of the 3D topology in the vicinity of each glycosite. Of the 18 glycosites in the 3D structure, 16 are predicted to be present in HLA peptides. Although the glycans may occur throughout the HLA sequences (Supplementary Table S2), in 12 of these sequences the glycans are predicted to be present at the terminus of at least one putative HLA antigen. This observation suggests that these 12 glycosites may not interfere with antigen presentation in an HLA complex. This property is essential for the potential generation of antibodies against the underlying epitopes, but moreover, may lead to antibodies that target these carbohydrates on the S glycoprotein (38). Anti-carbohydrate antibodies have been shown to be neutralizing in other viruses, such as HIV (40), and therefore glycosylated peptides can offer an alternative to more traditional peptide epitopes. Targeting glycans as epitopes is most effective when the glycans or their clusters are significantly different from self, and thus are not immunologically tolerated (6). Although viruses exploit the host glycosylation machinery in their biosynthesis, differences from host glycan distributions can occur when for example the virus cloaks itself so densely in glycosites that the glycans are not accessible to glycan processing enzymes, due to steric crowding, and remain in their high mannose form (17). Examples of this are seen in the high-mannose clusters in some strains of influenza (17) and in HIV (41). 
a.

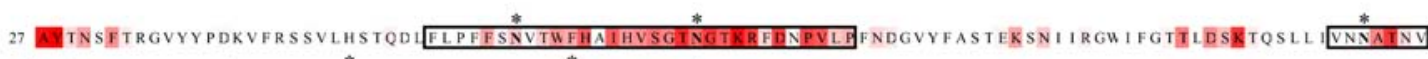

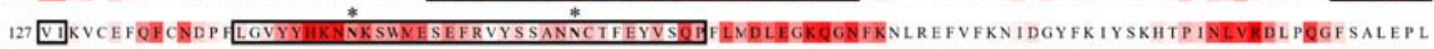

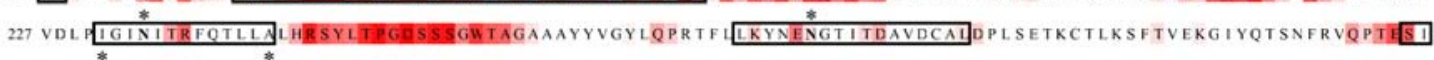

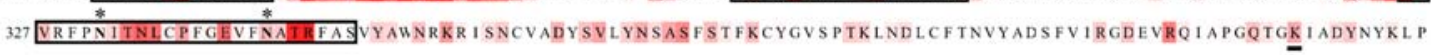
427 DDFTGCVI AUNSNEID SEVGGNYNYLYRLFRKSNLKPFERDISTEIYGAGSTPCNGVEGENCYFP LOSYG FEPINGVGYQPYRVVVLSFELLHAPATVCG

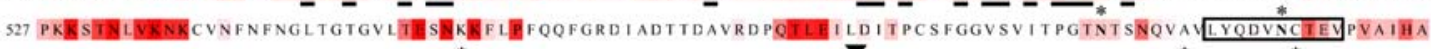

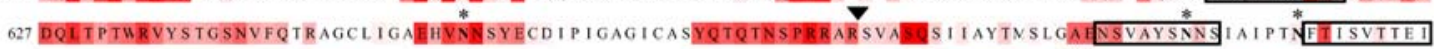

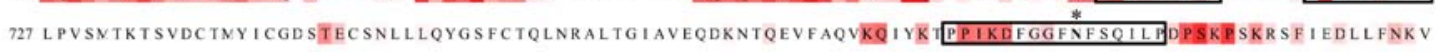

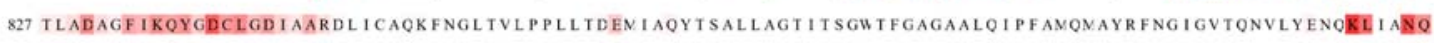
927 FNSAIGE I ODSLSSTASALGKLQDVVNQNAQALNTLVKQLSSNFGA ISSVLNDILSRLDKVEAEVQIDRLITGRLQSLQTYVTQQLIRAAEIRASANLAA

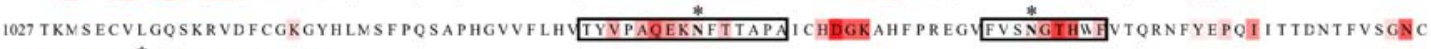

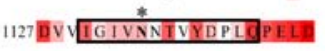

b.

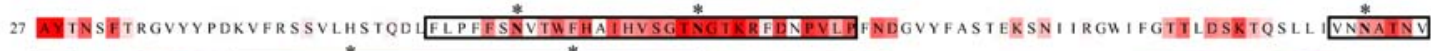

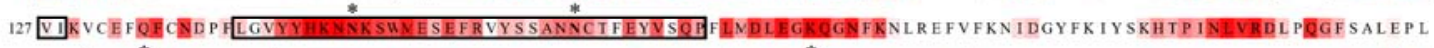
227 VDL

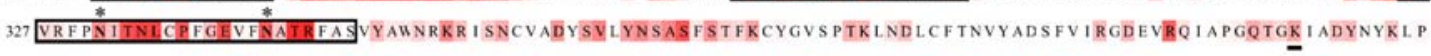

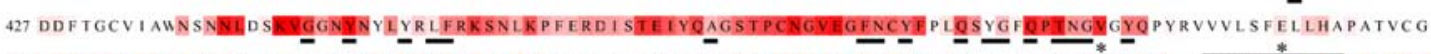

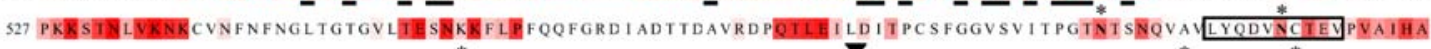

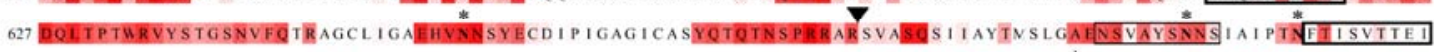

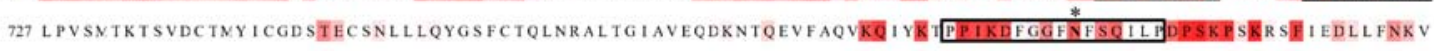
827 TLADAGF IKOYGDCLGDIAARDL I CAQKFNGLTVLPPLLTDEN IAQYT SALLAGT IT SGWTFGAGAALQ I PFANQNAYRFNG I GVTQNVLYENOEIIANQ 927 FNSA IGK IODSLSSTASALGKLQDVVNQNAQALNTLVKOLS SNFGAIS SVLND ILSRLDKVEAEVOIDRLITGRLQSLQTYVTQQLIRAAEIRASANLAA

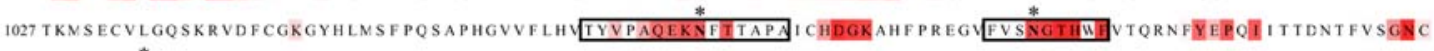
1127 DV TIVNNTVIDLGPEL

C.

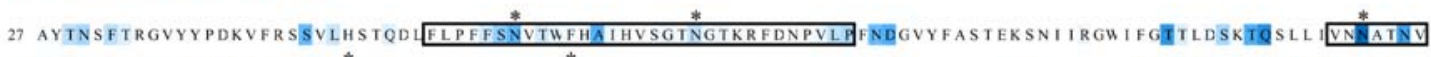

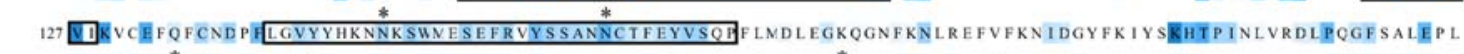

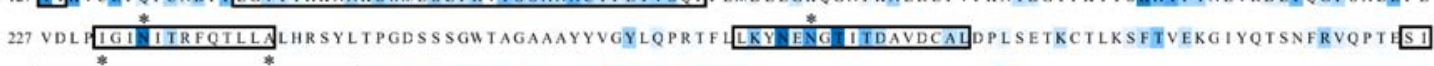

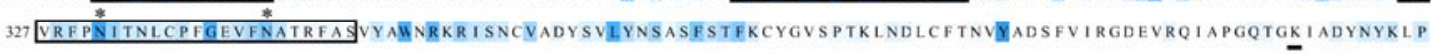
427 DDFTGCVIAUNSNNLDSKVGNYNYLYRLFRKSNLKPFERDISTEIYQAGSTPCNGVEGNCYFPLQSYGFPTNGVGYPYRVVVLSFELLLAPATVCG

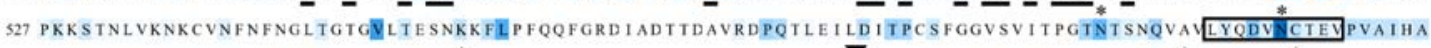

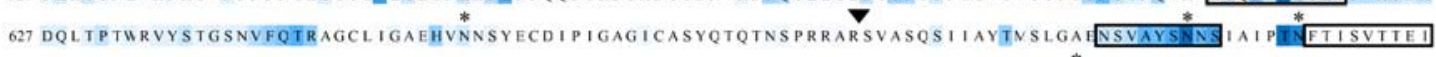

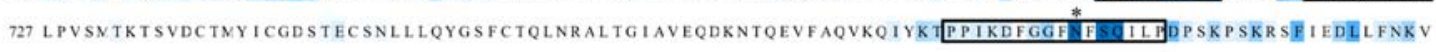

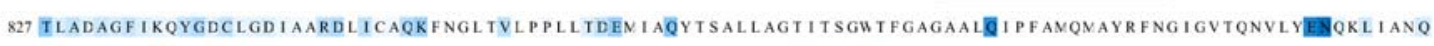

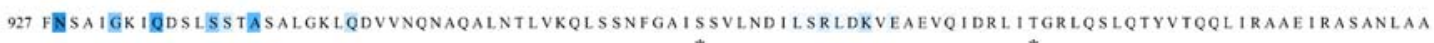
1027 TKMSECVLGQSKRVDFCGKGYHLMSFPQSAPHGVVFLH TYVPAQEKNFTTAPA CHDGKAHFPREG EVSNGTHWVITRNEYEPQI ITTDNTFVSGNC 1127 DV్ $\frac{*}{\text { GIVNNTYPPLOPELD }}$

Figure 2. Sequence of the S protein (NCBI: YP_009724390.1) used to generate the 3D model of the glycoprotein. Residues 1-26 and 1147-1273 were not included in the 3D structure due to a lack of relevant template structures. Sequences within a rectangle were predicted to consist of one or more HLA antigens using the RankPep server (imed.med.ucm.es/Tools/rankpep $(36,37)$ ). Glycosites are indicated with asterisks, residues reported to interact with the ACE2 receptor (42) are underlined, and the protease cleavage site is indicated with a triangle above the RS junction. a. The sequence is colored according to antibody accessibility computed for the site-specific glycoform from white to red (least to most accessible). b. Antibody accessibility computed for the non-glycosylated protein. $\mathbf{c}$. The difference in accessibilities between the site-specific and non-glycosylated glycoforms is plotted as the fold change in epitope accessibility during the simulation, from -4 (blue) to 0 (white), where blue indicates glycosylation-dependent surface shielding. 
From the perspective of vaccine development (43), targeting glycans as epitopes would be expected to benefit from matching the glycan microheterogeneity in the vaccine to that in the circulating virus, which requires additional consideration of the choice of cell type for vaccine production.

Comparison with epitopes in related coronavirus $\mathbf{S}$ glycoproteins. To illustrate the impact of glycosylation on epitope exposure, we aligned the 3D structure of the spike proteins from SARS-CoV-2 with those from co-crystal structures of SARS-CoV-1 and MERS that contained bound antibody fragments. The S glycoproteins of SARS-CoV-1 and CoV-2 share a high degree of structural similarity, with an average root-mean-squared difference (RMSD) in the C $\alpha$ positions of only $3.8 \AA$ (14). The MERS S glycoprotein also shares a similar trimeric structure with $\mathrm{CoV}-1$ and $\mathrm{CoV}-2$. From this alignment, the extent to which epitopes in the CoV-2 S glycoprotein might be inaccessible to known antibodies on the basis of structural differences in the glycoproteins or due to shielding by glycans on the CoV$2 \mathrm{~S}$ glycoprotein surface was inferred (Figure 3). Approximately $50 \%$ of the corresponding epitopes in the CoV-2 S glycoprotein are blocked by glycans from antibody binding, and only areas of the protein surface at the apex of the S1 domain appear to be accessible to known antibodies. Although this static epitope analysis doesn't take into account the plasticity of the glycans or the protein it does confirm that the RBD in the CoV-2 S glycoprotein should be accessible for antibody recognition, consistent with the analysis of the MD simulation data.

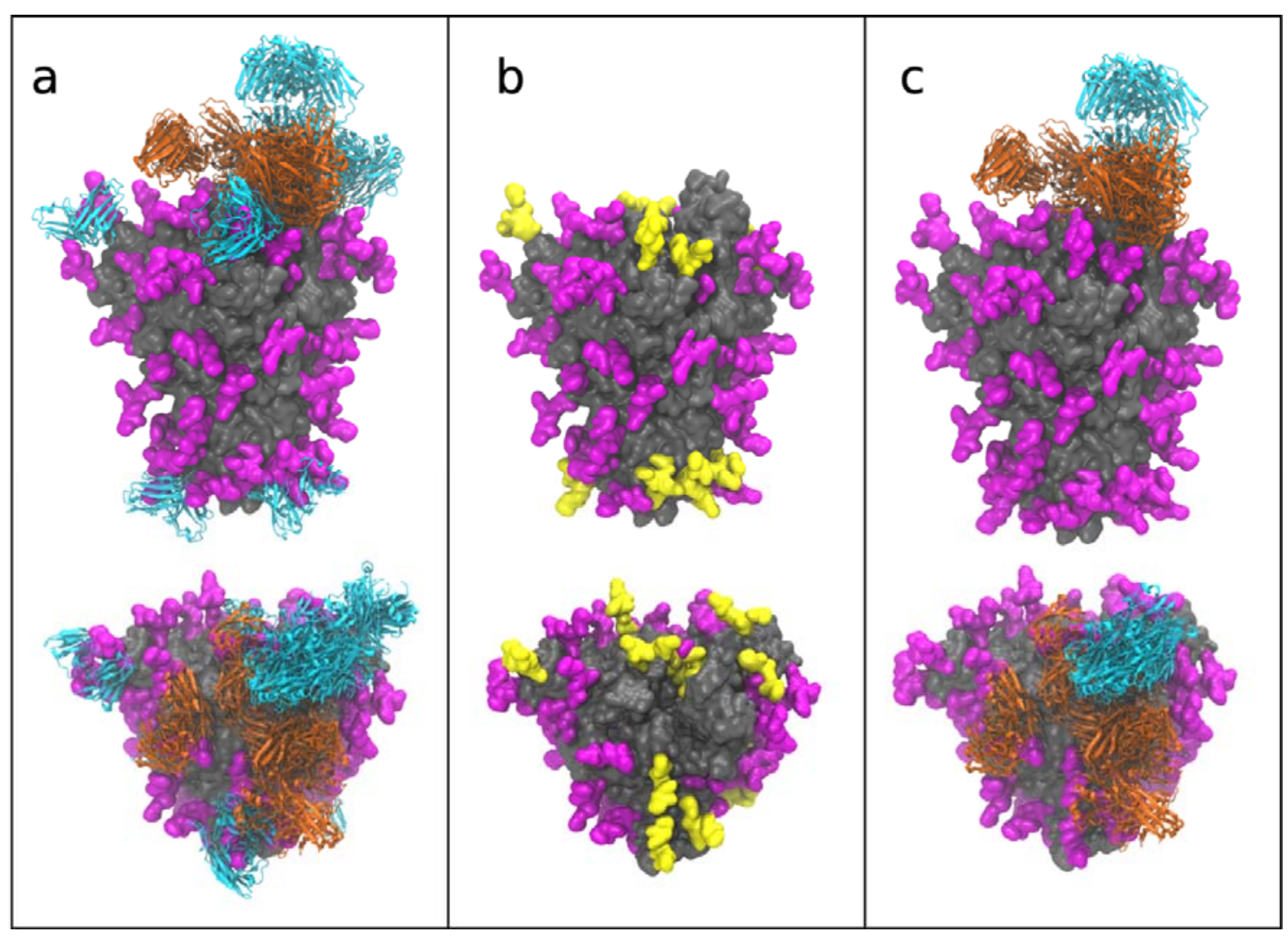

Figure 3. Glycan shielding of the SARS-CoV-2 S protein from known antibodies for the SARS-CoV-1 and MERS S proteins. a. Side view (upper panels) and top view (lower panels) of the SARS-CoV-2 S protein (grey surface) with homogeneous complex glycosylation (magenta) showing aligned antibody fragments (ribbons) from co-complexes with the S glycoproteins from SARS-CoV-1 (orange) and MERS (cyan) (44-56). b. Glycans 
present on SARS-CoV-2 S glycoprotein that are incompatible with known antibody positions due to steric overlap are shown in yellow. c. Potential antibody poses after elimination of epitopes blocked by S protein glycosylation. Images generated using VMD (32) version 1.9.3.

\section{Discussion}

The present study indicates that glycans shield approximately $40 \%$ of the underlying protein surface of the $S$ glycoprotein from antibody recognition, and that this value is relatively insensitive to glycan type. This suggests that although glycan microheterogeneity varies according to host cell type, the efficacy of antisera should not be impacted by such differences. In contrast, by analogy with influenza hemagglutinin $(57,58)$, variations in glycosite location arising from antigenic drift can be expected to have a profound effect on $\mathrm{S}$ protein antigenicity and potentially vaccine efficacy. Fortunately, the most accessible and largest epitope in the S protein consists of the ACE2 binding domain, where the virus cannot exploit glycan shielding or mutational changes to evade host immune response without potentially attenuating viral fitness. The requirement that the virus maintain the integrity of the ACE2 RBD suggests that a vaccine that includes this epitope may maintain efficacy despite antigenic drift, as long as the virus continues to target the same host receptor.

While overall shielding of the underlying protein surface does not appear to be highly sensitive to glycan microheterogeneity, it would likely impact the innate immune response by altering the ability of collectins and other lectins of the immune system to effectively bind to the $S$ protein and neutralize the virus (17), and may impact the adaptive immune response by altering the number of viable HLA antigens. Given that in humans, glycan microheterogeneity varies between individuals, and depends on many factors, including age (59), underlying disease $(60,61)$ and ethnicity $(62)$, access to 3D models of the S glycoprotein may aid in defining the molecular basis for the differential susceptibilities among individuals to COVID-19.

Lastly, the observation that homogeneously glycosylated glycoforms are predicted to display approximately the same shielding properties as those computed for the more relevant sitespecific glycoform suggests that such models can be usefully applied in advance of the report of experimental glycomics data. This final conclusion is significant as it enables the effects of glycosite alterations to be estimated in anticipation of seasonal antigenic drift.

\section{Methods}

SARS-CoV2 spike (S) protein structure - A 3D structure of the prefusion form of the $S$ protein (RefSeq: YP_009724390.1, UniProt: P0DTC2 SPIKE_SARS2), based on a Cryo-EM structure (PDB code 6VSB) (14), was obtained from the SWISS-MODEL server (swissmodel.expasy.org). The model has 95\% coverage (residues 27 to 1146) of the $S$ protein.

S protein glycoform generation - Five unique 3D models for the glycosylated glycoprotein were generated using the glycoprotein builder available at GLYCAM-Web (www.glycam.org) together with an in-house program that adjusts the asparagine side chain torsion angles and glycosidic linkages within known low-energy ranges (63) to relieve any atomic overlaps with the core protein, as described previously $(57,64)$. The site specific 
glycans used to model a glycoform representative of the data obtained from the $\mathrm{S}$ glycoprotein expressed in HEK293 cells (16), are presented in Supplementary Table S1.

Energy minimization and Molecular dynamics (MD) simulations - Each glycosylated structure was placed in a periodic box of approximately 130,000 TIP3P water molecules (65) with a $10 \AA$ buffer between the glycoprotein and the box edge. Energy minimization of all atoms was performed for 20,000 steps (10,000 steepest decent, followed by 10,000 conjugant gradient) under constant pressure $(1 \mathrm{~atm})$ and temperature $(300 \mathrm{~K})$ conditions. All MD simulations were performed under $\mathrm{nPT}$ conditions with the CUDA implementation of the PMEMD $(66,67)$ simulation code, as present in the Amber14 software suite $(68)$. The GLYCAM06j force field (69) and Amber14SB force field (70) were employed for the carbohydrate and protein moieties, respectively. A Berendsen barostat with a time constant of 1 ps was employed for pressure regulation, while a Langevin thermostat with a collision frequency of $2 \mathrm{ps}^{-1}$ was employed for temperature regulation. A nonbonded interaction cutoff of $8 \AA$ was employed. Long-range electrostatics were treated with the particle-mesh Ewald (PME) method (71). Covalent bonds involving hydrogen were constrained with the SHAKE algorithm, allowing an integration time step of 2 fs (72) to be employed. The energy minimized coordinates were equilibrated at $300 \mathrm{~K}$ over $400 \mathrm{ps}$ with restraints on the solute heavy atoms. Each system was then equilibrated with restraints on the $\mathrm{C} \alpha$ atoms of the protein for 1ns, prior to initiating 3 independent production MD simulations with random starting seeds for a total time of $0.75 \mu \mathrm{s}$, with no restraints applied.

Antigenic surface analysis. A series of 3D structure snapshots of the simulation were taken at $1 \mathrm{~ns}$ intervals and analysed in terms of their ability to interact with a spherical probe based on the average size of hypervariable loops present in an antibody complementarity determining region (CDR) (Figure 3). The percentage of simulation time each residue was exposed to the AbASA probe was calculated and plotted onto both the 3D structure (Figure 1) and sequence (Figure 2). The average AbASA over the course of the simulations was also calculated for each glycoform and compared to nude protein (Table 2).

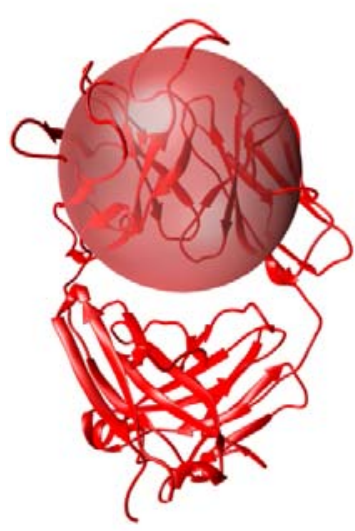

$\mathrm{mAb} \times 5$

(PDB ID: 2B4C)

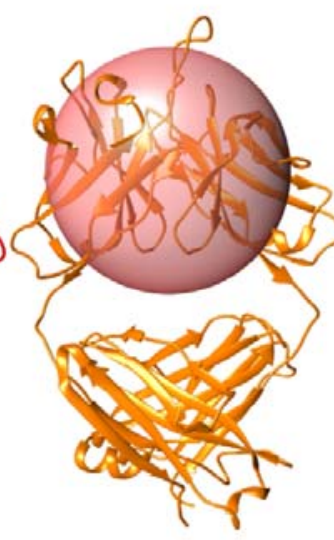

$\mathrm{mAb} b 12$

(PDB ID: 2NY7)

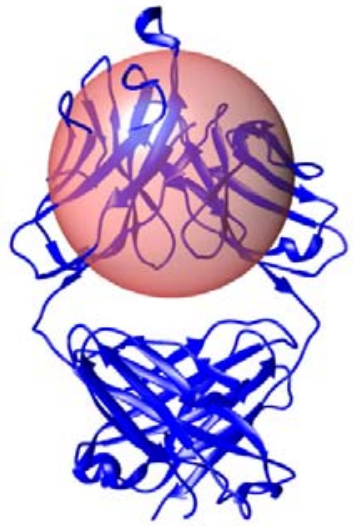

$\mathrm{mAb}$ b17

(PDB ID: 1G9M)

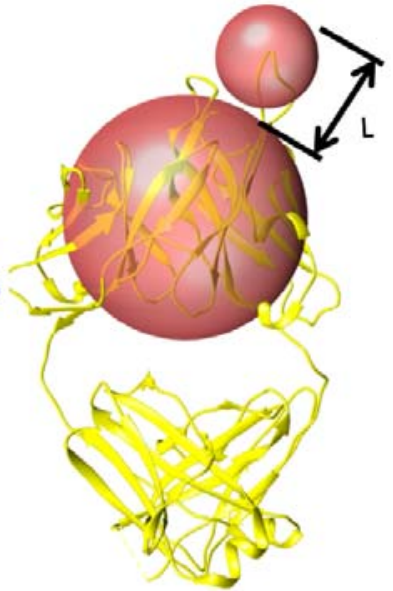

mAb PGT128

(PDB ID: 3TYG)

Figure 4. Antibody accessible surface area estimation using a pair of spherical probes. To estimate the AbASA, a spherical probe was derived (radius $7.2 \AA$, smaller sphere) that approximates the average size of the hypervariable loops from four anti-gp120 antibodies, in 
which the epitopes were either protein surface residues (PDB IDs: 2B4C (73), 2NY7 (74), 1G9M (75)) or both carbohydrate and protein residues: (3TYG (76)). This probe size may be compared to values of 5 and $10 \AA$ employed previously to estimate antigenic surface area (77). Changes in the solvent accessible surface area (SASA) showed no shielding by glycans and thus a simple SASA model was not useful for this analysis (77). Additionally, to account for the presence of the beta-sheet framework in the antibody variable fragment $(\mathrm{Fv})$, we introduced a second larger probe $(18.6 \AA)$ sufficient to approximately enclose that domain. The antigenic surface area is then defined as sum of the surface areas of any protein residues that make contact with the CDR probe, provided that the CDR probe is proximal to the $\mathrm{FV}$ probe. This latter requirement is governed by " $\mathrm{L}$ ", which requires that the distance between the CDR-antigen contact site and the Fv probe surface be less than the length $(10.4 \AA)$ of the longest CDR loop in mAb PGT128. PGT128 was chosen for this reference as it contains a particularly long CDR loop that penetrates the glycan shield of gp120. Images generated with UCSF Chimera (78).

\section{Supporting Information}

Coordinates in pdb format for each glycoform of the $\mathrm{S}$ glycoprotein are available for download from GLYCAM-Web (www.glycam.org).

\section{Acknowledgments}

R.J.W. thanks the National Institutes of Health (U01 CA207824 and P41 GM103390) for financial support.

\section{Author Contributions}

O.C.G. and R.J.W. designed the research; O.C.G., D. M., K. I., and R.J.W. performed the research; R.J.W. wrote the paper.

\section{Competing Interests}

The authors declare no competing interests.

\section{References}

1. W.H.O. Coronavirus disease 2019 (Covid-19) Situation Report. 202031 March. Report No.: 77.

2. Depetris RS, Julien JP, Khayat R, Lee JH, Pejchal R, Katpally U, Cocco N, Kachare M, Massi E, David KB, Cupo A, Marozsan AJ, Olson WC, Ward AB, Wilson IA, Sanders RW, Moore JP. Partial enzymatic deglycosylation preserves the structure of cleaved recombinant HIV-1 envelope glycoprotein trimers. J Biol Chem. 2012;287(29):2423954. Epub 2012/05/31. doi: 10.1074/jbc.M112.371898. PubMed PMID: 22645128; PMCID: PMC3397850.

3. Pereira MS, Alves I, Vicente M, Campar A, Silva MC, Padrao NA, Pinto V, Fernandes A, Dias AM, Pinho SS. Glycans as Key Checkpoints of T Cell Activity and Function. Front Immunol. 2018;9:2754. Epub 2018/12/13. doi: 10.3389/fimmu.2018.02754. PubMed PMID: 30538706; PMCID: PMC6277680. 
4. Baum LG, Cobb BA. The direct and indirect effects of glycans on immune function. Glycobiology. 2017;27(7):619-24. Epub 2017/05/02. doi: 10.1093/glycob/cwx036. PubMed PMID: 28460052.

5. Vigerust DJ, Shepherd VL. Virus glycosylation: role in virulence and immune interactions. Trends in microbiology. 2007;15(5):211-8. Epub 2007/04/03. doi: 10.1016/j.tim.2007.03.003. PubMed PMID: 17398101.

6. Crispin M, Doores KJ. Targeting host-derived glycans on enveloped viruses for antibody-based vaccine design. Curr Opin Virol. 2015;11:63-9. Epub 2015/03/10. doi: 10.1016/j.coviro.2015.02.002. PubMed PMID: 25747313; PMCID: PMC4827424.

7. Casals C, Campanero-Rhodes MA, Garcia-Fojeda B, Solis D. The Role of Collectins and Galectins in Lung Innate Immune Defense. Front Immunol. 2018;9:1998. Epub 2018/09/21. doi: 10.3389/fimmu.2018.01998. PubMed PMID: 30233589; PMCID: PMC6131309.

8. Hutter J, Rodig JV, Hoper D, Seeberger PH, Reichl U, Rapp E, Lepenies B. Toward animal cell culture-based influenza vaccine design: viral hemagglutinin N-glycosylation markedly impacts immunogenicity. J Immunol. 2013;190(1):220-30. Epub 2012/12/12. doi: 10.4049/jimmunol.1201060. PubMed PMID: 23225881.

9. Stevens J, Blixt O, Tumpey TM, Taubenberger JK, Paulson JC, Wilson IA. Structure and receptor specificity of the hemagglutinin from an $\mathrm{H} 5 \mathrm{~N} 1$ influenza virus. Science. 2006;312(5772):404-10. Epub 2006/03/18. doi: 10.1126/science.1124513. PubMed PMID: 16543414.

10. Cotter CR, Jin H, Chen Z. A single amino acid in the stalk region of the H1N1pdm influenza virus HA protein affects viral fusion, stability and infectivity. PLoS Pathog. 2014;10(1):e1003831. Epub 2014/01/07. doi: 10.1371/journal.ppat.1003831. PubMed PMID: 24391498; PMCID: PMC3879363.

11. Li Y, Bostick DL, Sullivan CB, Myers JL, Griesemer SB, Stgeorge K, Plotkin JB, Hensley SE. Single hemagglutinin mutations that alter both antigenicity and receptor binding avidity influence influenza virus antigenic clustering. J Virol. 2013;87(17):990410. Epub 2013/07/05. doi: 10.1128/JVI.01023-13. PubMed PMID: 23824816; PMCID: PMC3754131.

12. Altman MO, Angel M, Kosik I, Trovao NS, Zost SJ, Gibbs JS, Casalino L, Amaro RE, Hensley SE, Nelson MI, Yewdell JW. Human Influenza A Virus Hemagglutinin Glycan Evolution Follows a Temporal Pattern to a Glycan Limit. mBio. 2019;10(2). Epub 2019/04/04. doi: 10.1128/mBio.00204-19. PubMed PMID: 30940704; PMCID: PMC6445938.

13. Zost SJ, Parkhouse K, Gumina ME, Kim K, Diaz Perez S, Wilson PC, Treanor JJ, Sant AJ, Cobey S, Hensley SE. Contemporary H3N2 influenza viruses have a glycosylation site that alters binding of antibodies elicited by egg-adapted vaccine strains. Proc Natl Acad Sci U S A. 2017;114(47):12578-83. Epub 2017/11/08. doi: 10.1073/pnas.1712377114. PubMed PMID: 29109276; PMCID: PMC5703309.

14. Wrapp D, Wang N, Corbett KS, Goldsmith JA, Hsieh CL, Abiona O, Graham BS, McLellan JS. Cryo-EM structure of the 2019-nCoV spike in the prefusion conformation. Science. 2020. Epub 2020/02/23. doi: 10.1126/science.abb2507. PubMed PMID: 32075877.

15. Yuan Y, Cao D, Zhang Y, Ma J, Qi J, Wang Q, Lu G, Wu Y, Yan J, Shi Y, Zhang X, Gao GF. Cryo-EM structures of MERS-CoV and SARS-CoV spike glycoproteins reveal the dynamic receptor binding domains. Nat Commun. 2017;8:15092. Epub 2017/04/11. doi: 10.1038/ncomms15092. PubMed PMID: 28393837; PMCID: PMC5394239. 
16. Watanabe Y, Allen JD, Wrapp D, McLellan JS, Crispin M. Site-specific analysis of the SARS-CoV-2 glycan shield. BioRxiv. 2020. Epub March 28, 2020. doi: DOI: 10.1101/2020.03.26.010322.

17. Khatri K, Klein JA, White MR, Grant OC, Leymarie N, Woods RJ, Hartshorn KL, Zaia J. Integrated Omics and Computational Glycobiology Reveal Structural Basis for Influenza A Virus Glycan Microheterogeneity and Host Interactions. Mol Cell Proteomics. 2016;15(6):1895-912. doi: 10.1074/mcp.M116.058016.

18. An Y, Parsons LM, Jankowska E, Melnyk D, Joshi M, Cipollo JF. N-Glycosylation of Seasonal Influenza Vaccine Hemagglutinins: Implication for Potency Testing and Immune Processing. J Virol. 2019;93(2). Epub 2018/10/26. doi: 10.1128/JVI.01693-18. PubMed PMID: 30355697; PMCID: PMC6321900.

19. An Y, Rininger JA, Jarvis DL, Jing X, Ye Z, Aumiller JJ, Eichelberger M, Cipollo JF. Comparative Glycomics Analysis of Influenza Hemagglutinin (H5N1) Produced in Vaccine Relevant Cell Platforms. J Proteome Res. 2013;12(8):3707-20. doi: 10.1021/pr400329k.

20. Homans SW, Dwek RA, Rademacher TW. Solution Conformations of N-Linked Oligosaccharides. Biochemistry. 1987;26(21):6571-8. doi: 10.1021/bi00395a001.

21. Homans SW, Dwek RA, Boyd J, Mahmoudian M, Richards WG, Rademacher TW. Conformational Transitions in N-Linked Oligosaccharides. Biochemistry. 1986;25(20):6342-50. doi: 10.1021/bi00368a076.

22. Woods RJ. Predicting the Structures of Glycans, Glycoproteins, and Their Complexes. Chemical Reviews. 2018;118(17):8005-24. doi: 10.1021/acs.chemrev.8b00032. PubMed PMID: 30091597.

23. Yamaguchi T, Sakae Y, Zhang Y, Yamamoto S, Okamoto Y, Kato K. Exploration of Conformational Spaces of High-Mannose-Type Oligosaccharides by an NMR-Validated Simulation. Angewandte Chemie-International Edition. 2014;53(41):10941-4. doi: 10.1002/anie.201406145. PubMed PMID: WOS:000343750300019.

24. Sawen E, Stevensson B, Ostervall J, Maliniak A, Widmalm G. Molecular conformations in the pentasaccharide LNF-1 derived from NMR spectroscopy and molecular dynamics simulations. J Phys Chem B. 2011;115(21):7109-21. doi: 10.1021/jp2017105. PubMed PMID: 21545157.

25. Jo S, Qi Y, Im W. Preferred conformations of N-glycan core pentasaccharide in solution and in glycoproteins. Glycobiology. 2016;26(1):19-29. Epub 2015/09/26. doi: 10.1093/glycob/cwv083. PubMed PMID: 26405106; PMCID: PMC4672150.

26. Harbison A, Fadda E. An atomistic perspective on ADCC quenching by corefucosylation of IgG1 Fc N-glycans from enhanced sampling molecular dynamics. Glycobiology. 2019. Epub 2019/12/13. doi: 10.1093/glycob/cwz101. PubMed PMID: 31829411.

27. Hang I, Lin CW, Grant OC, Fleurkens S, Villiger TK, Soos M, Morbidelli M, Woods RJ, Gauss R, Aebi M. Analysis of site-specific N-glycan remodeling in the endoplasmic reticulum and the Golgi. Glycobiology. 2015;25(12):1335-49. doi: 10.1093/glycob/cwv058. PubMed PMID: 26240167; PMCID: PMC4634314.

28. Amaro RE, Li WW. Molecular-level simulation of pandemic influenza glycoproteins. Methods Mol Biol. 2012;819:575-94. Epub 2011/12/21. doi: 10.1007/978-1-61779-4650_34. PubMed PMID: 22183559; PMCID: PMC3352029.

29. Singh A, Tessier MB, Pederson K, Wang X, Venot A, Boons GJ, Prestegard JH, Woods RJ. Extension of the GLYCAM force field parameters for Glycosaminoglycans and their validation. Can J Chem. 2016;94:1-9.

30. Kirschner KN, Yongye AB, Tschampel SM, González-Outeiriño J, Daniels CR, Foley BL, Woods RJ. GLYCAM06: A Generalizable Biomolecular Force Field. 
Carbohydrates. J Comput Chem. 2008;29(4):622-55. Epub 2007. doi:

10.1002/jcc.20820; PMCID: PMID: 17849372.

31. Tessier MB, DeMarco ML, Yongye AB, Woods RJ. Extension of the GLYCAM06 Biomolecular Force Field to Lipids, Lipid Bilayers and Glycolipids. Mol Simul. 2008;34(4):349-64. doi: 10.1080/08927020701710890.

32. Humphrey W, Dalke A, Schulten K. VMD - Visual Molecular Dynamics. J Mol Graphics. 1996;14:33-8.

33. Hubbard SJ, Thornton JM. NACCESS. 2.1.1 ed. London: University College London; 1993.

34. Horiya S, MacPherson IS, Krauss IJ. Recent strategies targeting HIV glycans in vaccine design. Nat Chem Biol. 2014;10(12):990-9. Epub 2014/11/14. doi:

10.1038/nchembio.1685. PubMed PMID: 25393493; PMCID: PMC4431543.

35. Doores KJ. The HIV glycan shield as a target for broadly neutralizing antibodies. FEBS J. 2015;282(24):4679-91. Epub 2015/09/29. doi: 10.1111/febs.13530. PubMed PMID: 26411545; PMCID: PMC4950053.

36. Reche PA, Glutting JP, Zhang H, Reinherz EL. Enhancement to the RANKPEP resource for the prediction of peptide binding to MHC molecules using profiles. Immunogenetics. 2004;56(6):405-19. Epub 2004/09/07. doi: 10.1007/s00251-004-0709-7. PubMed PMID: 15349703.

37. Reche PA, Glutting JP, Reinherz EL. Prediction of MHC class I binding peptides using profile motifs. Hum Immunol. 2002;63(9):701-9. Epub 2002/08/15. doi: 10.1016/s01988859(02)00432-9. PubMed PMID: 12175724.

38. Avci FY, Li X, Tsuji M, Kasper DL. A mechanism for glycoconjugate vaccine activation of the adaptive immune system and its implications for vaccine design. Nature:

Medicine. 2011;17(12):1602-9. Epub 2011/11/22. doi: 10.1038/nm.2535. PubMed PMID: 22101769; PMCID: PMC3482454.

39. Malaker SA, Ferracane MJ, Depontieu FR, Zarling AL, Shabanowitz J, Bai DL, Topalian SL, Engelhard VH, Hunt DF. Identification and Characterization of Complex Glycosylated Peptides Presented by the MHC Class II Processing Pathway in Melanoma. J Proteome Res. 2017;16(1):228-37. Epub 2016/08/24. doi:

10.1021/acs.jproteome.6b00496. PubMed PMID: 27550523; PMCID: PMC5218890.

40. Haji-Ghassemi O, Blackler RJ, Martin Young N, Evans SV. Antibody recognition of carbohydrate epitopes. Glycobiology. 2015;25(9):920-52. Epub 2015/06/03. doi: 10.1093/glycob/cwv037. PubMed PMID: 26033938.

41. Bonomelli C, Doores KJ, Dunlop DC, Thaney V, Dwek RA, Burton DR, Crispin M, Scanlan CN. The Glycan Shield of HIV Is Predominantly Oligomannose Independently of Production System or Viral Clade. PLoS One. 2011;6(8):e23521. doi: 10.1371/journal.pone.0023521.

42. Lan J, Ge J, Yu J, Shan S, Zhou H, Fan S, Zhang Q, Shi X, Wang Q, Zhang L, Wang X. Crystal structure of the 2019-nCoV spike receptor-binding domain bound with the ACE2 receptor. BioRxiv. 2020. Epub February 20, 2020. doi: 10.1101/2020.02.19.956235.

43. Chang D, Zaia J. Why Glycosylation Matters in Building a Better Flu Vaccine. Mol Cell Proteomics. 2019;18(12):2348-58. Epub 2019/10/13. doi: 10.1074/mcp.R119.001491. PubMed PMID: 31604803; PMCID: PMC6885707.

44. Prabakaran P, Gan J, Feng Y, Zhu Z, Choudhry V, Xiao X, Ji X, Dimitrov DS. Structure of severe acute respiratory syndrome coronavirus receptor-binding domain complexed with neutralizing antibody. J Biol Chem. 2006;281(23):15829-36. Epub 2006/04/07. doi: 10.1074/jbc.M600697200. PubMed PMID: 16597622.

45. Hwang WC, Lin Y, Santelli E, Sui J, Jaroszewski L, Stec B, Farzan M, Marasco WA, Liddington RC. Structural basis of neutralization by a human anti-severe acute 
respiratory syndrome spike protein antibody, 80R. J Biol Chem. 2006;281(45):34610-6. Epub 2006/09/07. doi: 10.1074/jbc.M603275200. PubMed PMID: 16954221.

46. Pak JE, Sharon C, Satkunarajah M, Auperin TC, Cameron CM, Kelvin DJ, Seetharaman J, Cochrane A, Plummer FA, Berry JD, Rini JM. Structural insights into immune recognition of the severe acute respiratory syndrome coronavirus $\mathrm{S}$ protein receptor binding domain. J Mol Biol. 2009;388(4):815-23. Epub 2009/03/28. doi: 10.1016/j.jmb.2009.03.042. PubMed PMID: 19324051; PMCID: PMC7094495.

47. Ying T, Prabakaran P, Du L, Shi W, Feng Y, Wang Y, Wang L, Li W, Jiang S, Dimitrov DS, Zhou T. Junctional and allele-specific residues are critical for MERS-CoV neutralization by an exceptionally potent germline-like antibody. Nat Commun. 2015;6:8223. Epub 2015/09/16. doi: 10.1038/ncomms9223. PubMed PMID: 26370782; PMCID: PMC4571279.

48. Wang L, Shi W, Joyce MG, Modjarrad K, Zhang Y, Leung K, Lees CR, Zhou T, Yassine HM, Kanekiyo M, Yang ZY, Chen X, Becker MM, Freeman M, Vogel L, Johnson JC, Olinger G, Todd JP, Bagci U, Solomon J, Mollura DJ, Hensley L, Jahrling P, Denison MR, Rao SS, Subbarao K, Kwong PD, Mascola JR, Kong WP, Graham BS. Evaluation of candidate vaccine approaches for MERS-CoV. Nat Commun. 2015;6:7712. Epub 2015/07/29. doi: 10.1038/ncomms8712. PubMed PMID: 26218507; PMCID: PMC4525294.

49. Li Y, Wan Y, Liu P, Zhao J, Lu G, Qi J, Wang Q, Lu X, Wu Y, Liu W, Zhang B, Yuen KY, Perlman S, Gao GF, Yan J. A humanized neutralizing antibody against MERS-CoV targeting the receptor-binding domain of the spike protein. Cell Res. 2015;25(11):123749. Epub 2015/09/24. doi: 10.1038/cr.2015.113. PubMed PMID: 26391698; PMCID: PMC4650419.

50. Chen Z, Bao L, Chen C, Zou T, Xue Y, Li F, Lv Q, Gu S, Gao X, Cui S, Wang J, Qin C, Jin Q. Human Neutralizing Monoclonal Antibody Inhibition of Middle East Respiratory Syndrome Coronavirus Replication in the Common Marmoset. J Infect Dis. 2017;215(12):1807-15. Epub 2017/05/05. doi: 10.1093/infdis/jix209. PubMed PMID: 28472421.

51. Pallesen J, Wang N, Corbett KS, Wrapp D, Kirchdoerfer RN, Turner HL, Cottrell CA, Becker MM, Wang L, Shi W, Kong WP, Andres EL, Kettenbach AN, Denison MR, Chappell JD, Graham BS, Ward AB, McLellan JS. Immunogenicity and structures of a rationally designed prefusion MERS-CoV spike antigen. Proc Natl Acad Sci U S A. 2017;114(35):E7348-E57. Epub 2017/08/16. doi: 10.1073/pnas.1707304114. PubMed PMID: 28807998; PMCID: PMC5584442.

52. Zhang S, Zhou P, Wang P, Li Y, Jiang L, Jia W, Wang H, Fan A, Wang D, Shi X, Fang X, Hammel M, Wang S, Wang X, Zhang L. Structural Definition of a Unique Neutralization Epitope on the Receptor-Binding Domain of MERS-CoV Spike Glycoprotein. Cell Rep. 2018;24(2):441-52. Epub 2018/07/12. doi:

10.1016/j.celrep.2018.06.041. PubMed PMID: 29996104; PMCID: PMC7104183.

53. Wang L, Shi W, Chappell JD, Joyce MG, Zhang Y, Kanekiyo M, Becker MM, van Doremalen N, Fischer R, Wang N, Corbett KS, Choe M, Mason RD, Van Galen JG, Zhou T, Saunders KO, Tatti KM, Haynes LM, Kwong PD, Modjarrad K, Kong WP, McLellan JS, Denison MR, Munster VJ, Mascola JR, Graham BS. Importance of Neutralizing Monoclonal Antibodies Targeting Multiple Antigenic Sites on the Middle East Respiratory Syndrome Coronavirus Spike Glycoprotein To Avoid Neutralization Escape. J Virol. 2018;92(10). Epub 2018/03/09. doi: 10.1128/JVI.02002-17. PubMed PMID: 29514901; PMCID: PMC5923077.

54. Zhou H, Chen Y, Zhang S, Niu P, Qin K, Jia W, Huang B, Zhang S, Lan J, Zhang L, Tan $\mathrm{W}$, Wang X. Structural definition of a neutralization epitope on the N-terminal domain of 
MERS-CoV spike glycoprotein. Nat Commun. 2019;10(1):3068. Epub 2019/07/13. doi: 10.1038/s41467-019-10897-4. PubMed PMID: 31296843; PMCID: PMC6624210.

55. Walls AC, Xiong X, Park YJ, Tortorici MA, Snijder J, Quispe J, Cameroni E, Gopal R, Dai M, Lanzavecchia A, Zambon M, Rey FA, Corti D, Veesler D. Unexpected Receptor Functional Mimicry Elucidates Activation of Coronavirus Fusion. Cell. 2019;176(5):1026-39 e15. Epub 2019/02/05. doi: 10.1016/j.cell.2018.12.028. PubMed PMID: 30712865; PMCID: PMC6751136.

56. Wang N, Rosen O, Wang L, Turner HL, Stevens LJ, Corbett KS, Bowman CA, Pallesen J, Shi W, Zhang Y, Leung K, Kirchdoerfer RN, Becker MM, Denison MR, Chappell JD, Ward AB, Graham BS, McLellan JS. Structural Definition of a Neutralization-Sensitive Epitope on the MERS-CoV S1-NTD. Cell Rep. 2019;28(13):3395-405 e6. Epub 2019/09/26. doi: 10.1016/j.celrep.2019.08.052. PubMed PMID: 31553909; PMCID: PMC6935267.

57. Peng W, de Vries RP, Grant OC, Thompson AJ, McBride R, Tsogtbaatar B, Lee PS, Razi N, Wilson IA, Woods RJ, Paulson JC. Recent H3N2 Viruses Have Evolved Specificity for Extended, Branched Human-type Receptors, Conferring Potential for Increased Avidity. Cell Host Microbe. 2017;21(1):23-34. doi: 10.1016/j.chom.2016.11.004. PubMed PMID: 28017661.

58. Sun X, Jayaraman A, Maniprasad P, Raman R, Houser KV, Pappas C, Zeng H, Sasisekharan R, Katz JM, Tumpey TM. N-linked glycosylation of the hemagglutinin protein influences virulence and antigenicity of the 1918 pandemic and seasonal H1N1 influenza A viruses. J Virol. 2013;87(15):8756-66. doi: 10.1128/J VI.00593-13. PubMed PMID: 23740978; PMCID: PMC3719814.

59. Dall'Olio F, Vanhooren V, Chen CC, Slagboom PE, Wuhrer M, Franceschi C. Nglycomic biomarkers of biological aging and longevity: a link with inflammaging. Ageing Res Rev. 2013;12(2):685-98. Epub 2012/02/23. doi: 10.1016/j.arr.2012.02.002. PubMed PMID: 22353383.

60. Pavic T, Dilber D, Kifer D, Selak N, Keser T, Ljubicic D, Vukic Dugac A, Lauc G, Rumora L, Gornik O. N-glycosylation patterns of plasma proteins and immunoglobulin $\mathrm{G}$ in chronic obstructive pulmonary disease. J Transl Med. 2018;16(1):323. Epub 2018/11/23. doi: 10.1186/s12967-018-1695-0. PubMed PMID: 30463578; PMCID: PMC6249776.

61. Rudman N, Gornik O, Lauc G. Altered N-glycosylation profiles as potential biomarkers and drug targets in diabetes. FEBS Lett. 2019;593(13):1598-615. Epub 2019/06/20. doi: 10.1002/1873-3468.13495. PubMed PMID: 31215021.

62. Gebrehiwot AG, Melka DS, Kassaye YM, Rehan IF, Rangappa S, Hinou H, Kamiyama T, Nishimura SI. Healthy human serum N-glycan profiling reveals the influence of ethnic variation on the identified cancer-relevant glycan biomarkers. PLoS One. 2018;13(12):e0209515. Epub 2018/12/29. doi: 10.1371/journal.pone.0209515. PubMed PMID: 30592755; PMCID: PMC6310272.

63. Nivedha AK, Makeneni S, Foley BL, Tessier MB, Woods RJ. Importance of ligand conformational energies in carbohydrate docking: Sorting the wheat from the chaff. J Comput Chem. 2014;35(7):526-39. Epub 2014/01/01. doi: 10.1002/jcc.23517. PubMed PMID: 24375430; PMCID: PMC3936473.

64. Grant OC, Xue X, Ra D, Khatamian A, Foley BL, Woods RJ. Gly-Spec: a webtool for predicting glycan specificity by integrating glycan array screening data and 3D structure. Glycobiology. 2016;26(10):1027-8. Epub 2017/01/26. doi: 10.1093/glycob/cww094. PubMed PMID: 28120784; PMCID: PMC5072150. 
65. Jorgensen WL. Quantum and Statistical Mechanical Studies of Liquids. 10. Transferable Intermolecular Potential Functions for Water, Alcohols, and Ethers. Application to Liquid Water. J Am Chem Soc. 1981;103(2):335-40. doi: 10.1021/ja00392a016.

66. Salomon-Ferrer R, Götz AW, Poole D, Le Grand S, Walker RC. Routine Microsecond Molecular Dynamics Simulations with AMBER on GPUs. 2. Explicit Solvent Particle Mesh Ewald. J Chem Theory Comput. 2013;9(9):3878-88. doi: 10.1021/ct400314y.

67. Gotz AW, Williamson MJ, Xu D, Poole D, Le Grand S, Walker RC. Routine Microsecond Molecular Dynamics Simulations with AMBER on GPUs. 1. Generalized Born. J Chem Theory Comput. 2012;8(5):1542-55. Epub 2012/05/15. doi: 10.1021/ct200909j. PubMed PMID: 22582031; PMCID: 3348677.

68. Case DA, Babin V, Berryman JT, Betz RM, Cai Q, Cerutti DS, T.E. Cheatham I, Darden TA, Duke RE, Gohlke H, Goetz AW, Gusarov S, Homeyer N, Janowski P, Kaus J, Koloss váry I, Kovalenko A, Lee TS, LeGrand S, Luchko T, Luo R, Madej B, Merz KM, Paesani F, Roe DR, Roitberg A, Sagui C, Salomon-Ferrer R, Seabra G, Simmerling CL, Smith W, Swails J, Walker RC, Wang J, Wolf RM, Wu X, Kollman PA. AMBER 14. University of California, San Francisco2014.

69. Kirschner KN, Yongye AB, Tschampel SM, Gonzalez-Outeirino J, Daniels CR, Foley BL, Woods RJ. GLYCAM06: a generalizable biomolecular force field. Carbohydrates. J Comput Chem. 2008;29(4):622-55. Epub 2007/09/13. doi: 10.1002/jcc.20820. PubMed PMID: 17849372.

70. Maier JA, Martinez C, Kasavajhala K, Wickstrom L, Hauser KE, Simmerling C. ff14SB: Improving the Accuracy of Protein Side Chain and Backbone Parameters from ff99SB. J Chem Theory Comput. 2015;11(8):3696-713. Epub 2015/11/18. doi: 10.1021/acs.jctc.5b00255. PubMed PMID: 26574453; PMCID: PMC4821407.

71. Darden T, York D, Pedersen L. Particle mesh Ewald: An N. $\log (\mathrm{N})$ method for Ewald sums in large systems. The Journal of chemical physics. 1993;98:10089.

72. Ryckaert J-P, Ciccotti G, Berendsen HJC. Numerical integration of the Cartesian Equations of Motion of a System with Constraints: Molecular Dynamics of n-Alkanes. J Comput Phys. 1977;23(3):327-41.

73. Huang CC, Tang M, Zhang MY, Majeed S, Montabana E, Stanfield RL, Dimitrov DS, Korber B, Sodroski J, Wilson IA, Wyatt R, Kwong PD. Structure of a V3-containing HIV-1 gp120 core. Science. 2005;310(5750):1025-8. Epub 2005/11/15. doi: 10.1126/science.1118398. PubMed PMID: 16284180; PMCID: PMC2408531.

74. Zhou T, Xu L, Dey B, Hessell AJ, Van Ryk D, Xiang SH, Yang X, Zhang MY, Zwick MB, Arthos J, Burton DR, Dimitrov DS, Sodroski J, Wyatt R, Nabel GJ, Kwong PD. Structural definition of a conserved neutralization epitope on HIV-1 gp120. Nature. 2007;445(7129):732-7. Epub 2007/02/16. doi: 10.1038/nature05580. PubMed PMID: 17301785; PMCID: PMC2584968.

75. Kwong PD, Wyatt R, Majeed S, Robinson J, Sweet RW, Sodroski J, Hendrickson WA. Structures of HIV-1 gp120 envelope glycoproteins from laboratory-adapted and primary isolates. Structure. 2000;8(12):1329-39. Epub 2001/02/24. doi: 10.1016/s09692126(00)00547-5. PubMed PMID: 11188697.

76. Pejchal R, Doores KJ, Walker LM, Khayat R, Huang P-S, Wang S-K, Stanfield RL, Julien J-P, Ramos A, Crispin M, Depetris R, Katpally U, Marozsan A, Cupo A, Maloveste S, Liu Y, McBride R, Ito Y, Sanders RW, Ogohara C, Paulson JC, Feizi T, Scanlan CN, Wong C-H, Moore JP, Olson WC, Ward AB, Poignard P, Schief WR, Burton DR, Wilson IA. A Potent and Broad Neutralizing Antibody Recognizes and Penetrates the HIV Glycan Shield. Science. 2011;334(6059):1097-103. doi: 10.1126/science.1213256. 
77. Urbanowicz RA, Wang R, Schiel JE, Keck ZY, Kerzic MC, Lau P, Rangarajan S, Garagusi KJ, Tan L, Guest JD, Ball JK, Pierce BG, Mariuzza RA, Foung SKH, Fuerst TR. Antigenicity and Immunogenicity of Differentially Glycosylated Hepatitis C Virus E2 Envelope Proteins Expressed in Mammalian and Insect Cells. J Virol. 2019;93(7). Epub 2019/01/18. doi: 10.1128/JVI.01403-18. PubMed PMID: 30651366; PMCID: PMC6430559.

78. Pettersen EF, Goddard TD, Huang CC, Couch GS, Greenblatt DM, Meng EC, Ferrin TE. UCSF Chimera - A Visualization System for Exploratory Research and Analysis. J Comp Chem. 2004;25(13):1605-12. 